\title{
My Last Editorial
}

\author{
FRED DIE ROKEM
}

Theatre Research International is published in association with IFTR - the International Federation for Theatre Research - and renews its editorial team every three years. Therefore, before passing on the 'torch' to Elaine Aston, who will serve as the Senior Editor beginning with the next issue of TRI $(35,1)$, and to Charlotte Canning, the incoming Associate Editor, wishing them success, I want to thank Elaine for her cooperation and support as Associate Editor during my three-year term. I also want to thank the Assistant Editor during my term as editor, Kristina Hagström-Ståhl, for her help. The articles that have been published during these years have no doubt greatly profited from her comments and suggestions, as well as from those of the many anonymous reviewers whom I also want to thank for their invaluable assistance. I would also like to thank the book review editors, in particular Peter Boenisch, for keeping the readers of the journal up to date with the many developments of the field, as well as the staff at Cambridge University Press, in particular Ella Colvin, Sally Hoffman and James Carr for their professional navigation of the actual publication process. Finally - and no doubt most importantly I want to thank the scholars who have contributed their research to the journal, as well as the readers. The contributions and the subscriptions are steadily growing and this is certainly an encouraging sign.

My farewell issue is devoted to the encounter and interaction between performance/theatre and philosophy and the complex dialogue between these two fields and their respective discursive practices, an area of research which I have lately also become more directly involved in. The sites of thinking and research where performance/theatre and philosophy encounter each other and interact, sometimes in cooperation and sometimes in direct confrontation with each other, have a long and complex history and it is no exaggeration to claim that important aspects of Western philosophy - beginning with Socrates, Plato and Aristotle and including contemporary speech-act theory - have developed as a direct and in some cases even polemical response to the arts in general and to the theatre in particular.

Even if the issues raised by these as well as many other philosophers or thinkers have always been of importance for the work we do as researchers of theatre and performance, during recent years we have seen a more direct interest in the discursive formations of philosophy and theatre/performance and the interactions between them both among scholars and practitioners involved with different expressions of theatre and performance as well as among philosophers. This is not only an awareness of theory for the sake 
of understanding the phenomena researched by theatre and performance studies. We have rather, I believe, entered a phase of critical re-examination of the philosophical foundations of theatre and performance, of the forms of knowledge about ourselves and the world we live in which these cultural practices enhance and develop, of their ethical consequences and the epistemological assumptions they are based on. To what extent these developments signal new directions for theatre and performance studies is still too early to tell, but they certainly force us to re-examine some of the basic assumptions of the field.

The articles featured here are by researchers and practitioners from vastly different backgrounds and cultures, some of them usually writing in languages other than English, who are situated in different stages of their careers. The issue begins with Esa Kirkkopelti's programmatic analysis of the notion of the scene and the 'appearance' of the human figure within the scene as reflected by the writings of Plato and Aristotle. This connection, he argues, is also of vital importance for our understanding of the contemporary debates about the scene, including what has been termed the postdramatic theatre. In her article, Laura Cull discusses the relations between the practices of Artaud and the thinking of Deleuze, problematizing not only the distinctions between 'practice' and 'thinking' but also, but in a different way from Kirkkopelti, the notion of the human presence. After that, Martin Puchner examines the relations between philosophy and theatre in the work of Badiou, arguing that the source for this interdependence can be traced back to Plato. Interestingly, both Kirkkopelti and Puchner - and this can no doubt also be said about the thinking of Deleuze as well - focus on the writings of Plato. Plato is no doubt the initiator of the problematic but also creative liminal space between philosophy and performance. Candice Amich - in this year's winning contribution to the IFTR New Scholars' Prize, for which she is congratulated - presents the work of Coco Fusco in the light of Jacques Rancière's notion of 'dissensus' as the performance of a wrong, problematizing the notion of exile in performance. The bloc of articles focusing on the relations between philosophy and performance ends with the collaborative contribution by Helmar Schramm and Barbara Sušec Michieli. Their critical reflections on the forms of doubt and melancholy developed as a result of postcommunist realities, tracing in particular the Hamletian tradition of this collocation, concern not only the encounters between philosophy and performance, but also their critical role at a particular historical moment.

This issue of TRI also includes a performance dossier. It is the first time this new feature, presenting a specific performance from different perspectives, is included in the journal. This dossier, put together by Jane Wong Yeang Chui, begins with her own description and analysis of The King Lear Project directed by Ho Tzu Nyen and Fran Borgia performed in Belgium and Singapore, continues with an interview with Ho Tzu Nyen and concludes with an essay by performance scholar Paul Rae, who was one of the participants in this performance project. It is my hope that this dossier, which describes a performance based on critical essays about Shakespeare's play, will illuminate a project which otherwise would probably not receive the attention of the international community of theatre and performance scholars. It examines how research into theatre and performance becomes performance again. Or, in Ho Tzu Nyen's own words, 
I wanted to see if it was possible to 'return' written texts about performances back onto the stage - to embody them, to give them flesh and blood and hence render them to the unstable play of passion and human frailty, ugliness and beauty.

The interactions between thinking and performance and the ways in which we 'perform thinking' and 'think about performance' and it is not always possible to keep them apart - make the encounters between them both fruitful and enigmatic. 